\title{
ERRATUM
}

\section{Triple motor mapping: transcranial, bipolar, and monopolar mapping for supratentorial glioma resection adjacent to motor pathways}

TO THE READERSHIP: An error appeared in the article by Gogos et al. (Gogos AJ, Young JS, Morshed RA, et al. Triple motor mapping: transcranial, bipolar, and monopolar mapping for supratentorial glioma resection adjacent to motor pathways. J Neurosurg. Published online June 5, 2020. doi:10.3171/2020.3.JNS193434).
In Fig. 1, panel A1, the twist electrode is mistakenly depicted entering the skull. This has been corrected in the figure shown below.

The article has been corrected online as of November 27, 2020.

Andrew J. Gogos, MBBS, FRACS

University of California, San Francisco, CA

CORRESPONDING ARTICLE See pp 1728-1737.

INCLUDE WHEN CITING

Published online November 27, 2020; DOI: 10.3171/2020.10.JNS193434a.

CAANS 2021, except where prohibited by US copyright law

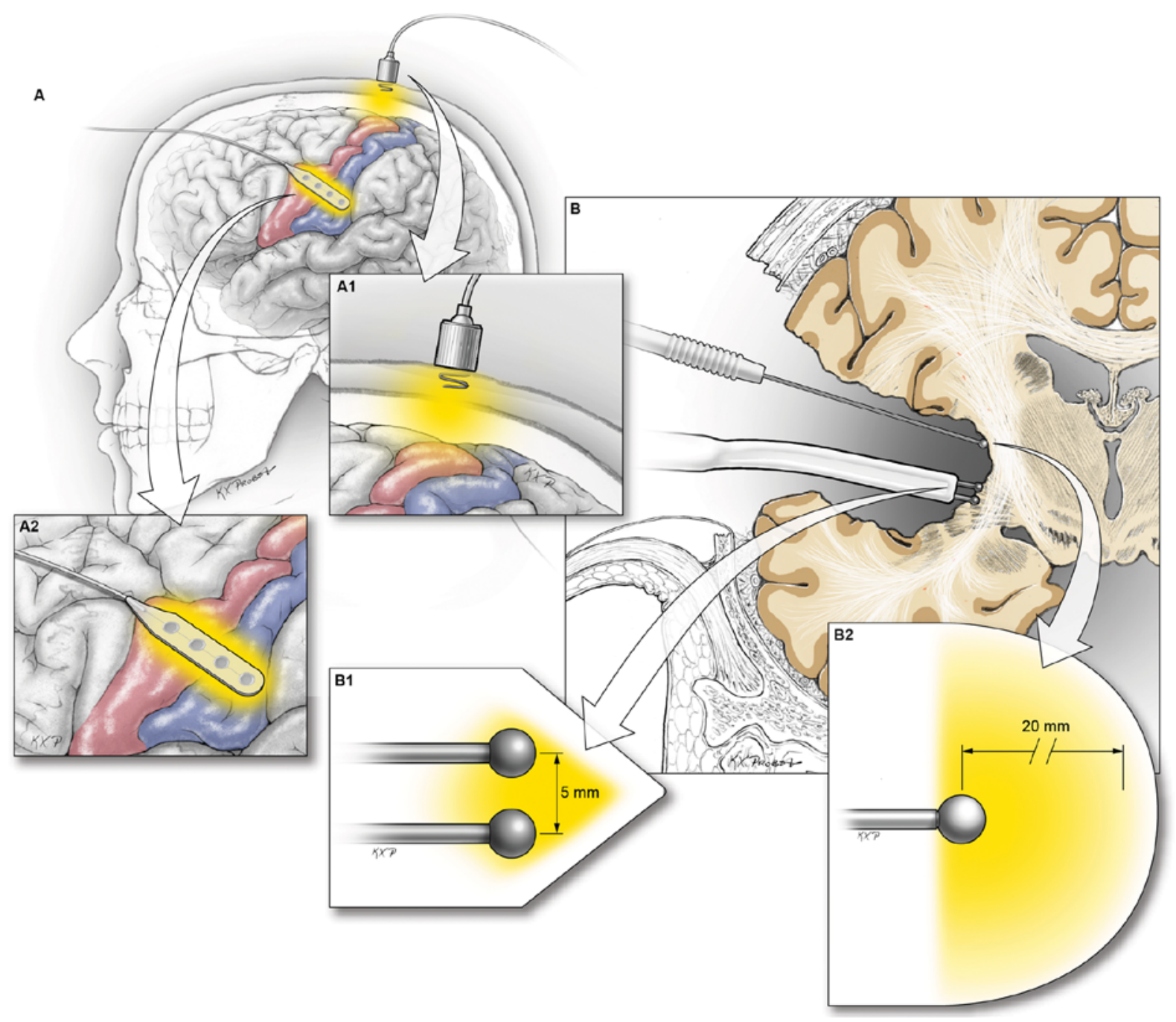

FIG. 1. Illustrations of the triple motor mapping technique. A: Illustration of monitoring with tcMEP and dcMEP electrodes. B: Illustration of subcortical mapping and current spread from bipolar and monopolar probes. Copyright Kenneth X. Probst. Published with permission. Figure is available in color online only. 